\title{
Regulación Financeira e crise: onte, hoxe e mañá
}

\section{Juan Quintás}

Universidade de Santiago, 13 de abril de 2018

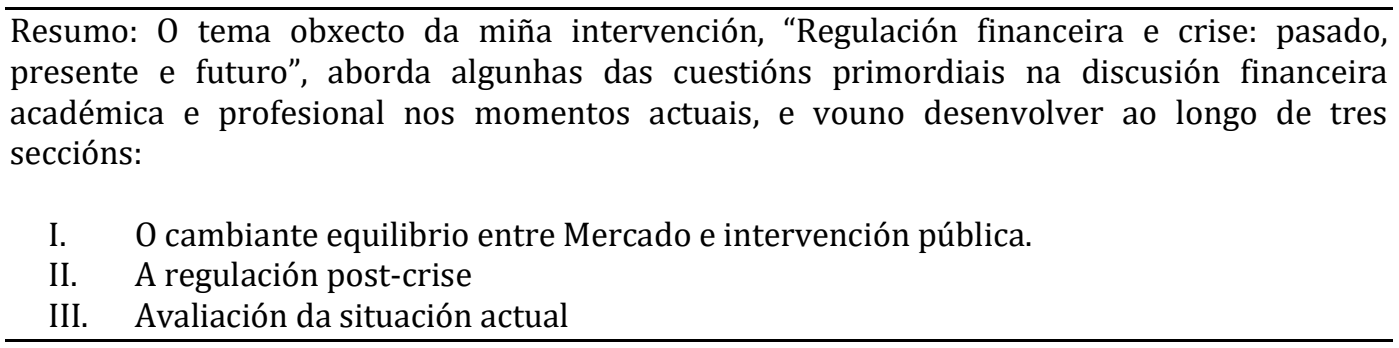

\section{1.- O CAMBIANTE EQUILIBRIO ENTRE MERCADO E INTERVENCIÓN PÚBLICA}

Malia o que se adoita argumentar, a poderosa capacidade produtiva do capitalismo non está só configurada polas forzas do libre mercado, senón tamén pola intervención pública (regulacións, intervención directa gobernamental, etc.), variando a importancia relativa de cada unha de acordo a unha dinámica pendular. 0 último medio século ilustra ben esta dinámica:

a. Durante as tres ou catro décadas que precederon á gran crise de 2008, prodúcese un notable retroceso do intervencionismo público e a posterior fortísima expansión dos mercados, como consecuencia de varios feitos entre os que cómpre destacar:

- $\quad$ A caída do comunismo

- A liberalización e as privatizacións rexistradas nas economías de mercado

- A liberalización dos fluxos internacionais de capital, traballo, bens e servizos

b. Pola contra, a partir da crise inicíase un redeseño da regulación no eido financeiro, no que se move a fronteira entre poderes públicos e mercados en prexuízo destes últimos.

A crise financeira marca, pois, o investimento no movemento pendular no eido financeiro. A explicación diso é que, malia na xénese da crise participaron intensamente tanto fallos da intervención pública como dos mercados, daquela tiveron na meirande parte dos casos o significado de, precisamente, unha insuficiencia da acción pública para frear o impulso desequilibrador orixinado nos mercados.

En efecto, os principais fallos públicos foron a compracencia cunha contorna perigosamente expansiva, con burbullas abraiantes nos mercados inmobiliarios, o descoido nas súas funcións supervisoras das entidades financeiras, a demora na aplicación de medidas correctoras e, nalgúns casos, o erróneo deseño das mesmas.

España é, probablemente, un dos casos máis evidentes de desaxeitada actuación pública en todos e cada un dos tipos de fallos públicos. De certo: 
1. Nin o Goberno nin o Banco de España actuaron para sofocar a enorme burbulla inmobiliaria española.

2. O Banco de España amosou unha sorprendente tolerancia con respecto ás malas prácticas de goberno nas entidades financeiras, prácticas que, por iso, se expandiron rapidamente na alongada e intensa senda expansiva que dominou o período que precedeu ao inicio da crise. Paralelamente tamén manifestou unha asombrosa neglixencia na apreciación do risco de insolvencia (véxase a carta da Asociación de Inspectores do Banco de España ao Vicepresidente Solbes, ou a recente intervención do Presidente daquela Asociación perante a Comisión de Investigación sobre a crise financeira de España no Congreso dos Diputados).

3. Goberno e Banco de España toleraron, e en certo modo animaron, á emisión de instrumentos híbridos como as participacións preferentes con destino aos clientes minoristas.

4. No capítulo de medidas para resolver a crise, aprecíase un extraordinario nivel de opacidade e incoherencia intertemporal, para concluír nunha precipitada adopción dunha fórmula xa aplicada no seu día con moi escaso éxito en Italia.

5. O neglixente atraso na resolución da crise -ao se refuxiar Goberno e Banco de España no wait and see- elevou enormemente o seu custo final (fiscal e de todo tipo).

6. No marco anterior, púidose ver aos gobernos rexionais vetando fusións economicamente razoables e forzando outras intrarrexionais para manter o seu control político das entidades, amparados no silencio cómplice e, nalgún caso, voluntariosa colaboración do Banco de España.

Malia a importancia dos fallos dos poderes públicos en xeral é obvio que a responsabilidade foi maior nos axentes privados ("mercado") pois foron as súas malas prácticas de goberno corporativo a primeira causa da crise, aínda que, sen dúbida, a actuación dos poderes públicos permite consideralos verdadeiros cooperadores necesarios para a gravidade daquela.

O movemento intensificador da regulación ao longo da última década arráigase así no recoñecemento xeral da completa insuficiencia da normativa daquela existente para erradicar aquelas malas prácticas, así como a súa incapacidade para controlar a dinámica explosiva exhibida polos mercados, evitando os riscos sistémicos, cuxa existencia se empeza a recoñecer paralelamente ao debilitación do mito da eficiencia do mercado e á crecente aceptación do carácter endóxeno das crises.

\section{2.- A REGULACIÓN POST-CRISE}

De todo o anterior derivouse un serio desprestixio das ideas, ata aquela dominantes, da desregulación e a autorregulación dos mercados financeiros, coa conseguinte emerxencia de propostas en orde a unha nova regulación financeira que, basicamente, se desenvolveu en torno a catro grandes liñas:

A. Xestión individual do risco e da gobernanza bancaria

B. A regulación macroprudencial

C. Os Bancos "sistemicamente importantes" 
D. Os conflitos de interese

\section{A) XESTIÓN INDIVIDUAL DO RISCO E A GOBERNANZA BANCARIA}

Durante 2009 as autoridades (véxanse as recomendacións do G-20 de novembro de 2009) e os expertos en bo goberno puxeron de relevo o importante papel que na xestación da gran crise tiveron as malas prácticas no goberno da Banca. Entre elas, dúas son as máis importantes:

1. Unha notable falta de sensibilidade con respecto ao risco por parte de moitos consellos de administración bancarios.

2. O control polos directivos dos consellos de administración, o que levou a unha preferencia polos resultados a curto prazo.

\section{FALTA DE SENSIBILIDADE PERANTE O RISCO}

$\mathrm{Na}$ orixe e desenvolvemento da crise, atopamos estratexias bancarias dunha aparente falta de sensibilidade con respecto ao risco a medio e longo prazos. Pódese dicir que, en moitos casos, os conselleiros ignoraban o risco ao que se enfrontaba a empresa, ben por ausencia dunha visión global do risco a nivel de grupo (non considerando, por exemplo, a contorna do risco transferido a entidades legalmente independentes -SIV, conduits ou hedge funds- pero ás que se lles concederan garantías ou financiamento), ou ben por simple incompetencia técnica en materia de riscos por parte dos conselleiros.

Para arrostrar esta situación, promovéronse regulacións que converteron en normas de obrigado cumprimento a regras de bo goberno como, por exemplo, a esixencia de cualificacións técnicas alomenos a boa parte dos conselleiros.

\section{A ERRADA PREFERENCIA POLOS BENEFICIOS A CURTO PRAZO}

Foi un importante factor coadxuvante da crise a frecuente tendencia dos directivos financeiros a favor de estratexias que maximizaban os beneficios a curto prazo, mesmo a asumindo graves riscos a medio prazo. Tal situación revela unha falta de aliñamento entre os intereses dos accionistas e os dos xestores, xunto co dominio destes últimos sobre os Consellos de Administración. Isto é novamente un caso no que o mal goberno corporativo contribuíu notablemente á xestación da crise porque, a miúdo, as estratexias que favorecían os bonos dos directivos poñían en perigo a supervivencia da entidade.

Os directivos prefiren que a súa retribución se basee nos resultados contables do exercicio ("vale máis paxaro na man ca un cento a voar" ...) e non os acadados a medio e longo prazo. Pero isto crea riscos para a empresa, pois os seus xestores poden ignorar proxectos con maiores valores actuais netos do fluxo de beneficios agardados a favor doutros que incidan máis intensamente nos beneficios do exercicio, pero que incorporen maiores riscos para o futuro (cando eles poden que xa marcharan a outra empresa ou se xubilaran).

O consello de administración ten a capacidade para seleccionar, substituír, incentivar e despedir aos directivos, así como para aprobar ou impedir a realización de proxectos de investimento relevantes. Así pois, se os consellos de administración (que representan os intereses dos accionistas) non impoñen os obxectivos societarios (supervivencia, beneficio a longo prazo) aos dos directivos, só pode ser ben pola súa ignorancia en materia de riscos ou, 
aínda peor, polo "secuestro" dos Consellos polos directivos, que fronte á masa pasiva de accionistas adoitan contar nesta actuación co apoio das posicións no Consello das grandes xestoras de fondos de investimento e de pensións, obsesionadas pola obtención de rendibilidade a curto prazo.

No caso de España, ademais de atopar unha situación con carácter xeral análoga á descrita, constátase un aspecto totalmente orixinal -e certamente desafortunado- como é o que unha malpocada regulación de 1985 posibilitou o control de nada menos que a metade do sistema bancario español (as caixas de aforros) aos políticos, malia a crítica permanente e estendida (nacional e internacionalmente) de tan perigosa situación. En efecto, unha lei de 1985 (a LORCA) facilitou a captura das caixas de aforros polos políticos, nutrindo os seus órganos de goberno e control atendendo máis a criterios de afinidade política cós de competencia, creando así un enorme problema de gobernanza que os poderes públicos non aceptaron resolver ata o colapso final, contribuíndo con iso á súa dureza.

Volvendo ao caso xeral, cómpre sinalar que a regulación post-crise tratou de neutralizar a perigosa preferencia polos beneficios a curto prazo, impoñendo a devindicación dos bonos en función dos beneficios a longo prazo, contemplando, ademais, a existencia de cláusulas de devolución no caso de mala evolución posterior dos resultados corporativos.

Por outra banda, a regulación post-crise tamén aspirou -malia que sen éxito completo- a debilitar a posición dos directivos que se atrincheiran fronte aos accionistas detrás dos obstáculos estatutarios ás OPAs (Ofertas Públicas de Adquisición) tales como a limitación do dereito ao voto, as blindaxes dos directivos, a imposición de escolla de conselleiros de forma gradual, etcétera.

\section{B. A REGULACION MACROPRUDENCIAL}

Para reducir significativamente a probabilidade de futuras crises financeiras, ou alomenos suavizar a súa dimensión, non chega con asegurar o bo goberno das institucións financeiras, senón que tamén é preciso controlar o risco sistémico, evitando que os mercados 1) emitan sinais errados aos xestores (os que, polo tanto, mesmo no caso de que actuasen seguindo boas prácticas, poderían conducir ás súas entidades en direccións erradas) ou que 2) colapsen, arrastrando a todo o sistema.

Malia que a investigación empírica xa aportara resultados bastante negativos con respecto á hipótese da eficiencia do mercado e a súa validez tamén fora criticada conceptualmente (por Joseph Stiglitz, por exemplo), non foi ata a crise de 2008, cos seus eventos nos mercados de capitais, cando se dispuxo dunha definitiva refutación dunha hipótese da que en 1978 Michael Jensen se atrevera a dicir que "non hai outra proposición en Economía que teña máis sólida evidencia empírica".

Efectivamente, os prezos de mercado con relación á banca (débeda e equity) previos ao crash de 2007 non proporcionaron indicación ningunha dos riscos existentes, asemade que os prezos das accións máis ben enviaron fortes sinais erróneos aos xestores, reforzando o convencemento deles en canto a que as estratexias agresivas de crecemento eran creadoras de valor. En canto aos CDS (credit default swaps) bancarios, a súa errónea mensaxe estaba contida nuns niveis de risco claramente infravalorados e nunha diferenciación de riscos demasiado reducida. Durante o período 2002-06, os diferenciais mantivéronse por debaixo 
dos 100 puntos básicos, reducíndose progresivamente os seus niveis e mesmo a diferenciación entre entidades.

Asemade, as presións dos analistas e as axencias de rating foron fortemente procíclicas: Lonxe de animar aos Bancos á constitución de "colchóns" de capital nos bos tempos anteriores a 2007, anticipando problemas futuros, a súa presión orientouse a que reducisen as ratios de capital, que eles xulgaban situadas a niveis ineficientemente elevados. Así mesmo, cando se analizan os rating realizados daquela para as entidades bancarias, obsérvase unha mínima dispersión entre elas, e ata unha revisión á alza nos meses previos á crise.

En resumo, a gran crise evidenciou que, nun mundo global, os mercados teñen dificultades para identificar os factores de risco sistémico. Por iso, para que a disciplina de mercado sexa un bo garante da estabilidade financeira, debe ir acompañada dunha axeitada regulación e supervisión.

Paralelamente, a crise tamén cuestionou a hexemonía académica dos defensores do carácter esóxeno das crises. En efecto hoxe, para moitos economistas (apoiándose nas ideas de ilustres colegas pertencentes a outra xeración, como Keynes, Kindleberger ou Minsky), as crises non son anomalías, senón o resultado do funcionamento normal do sistema. É dicir, son sistémicas ou endóxenas, no senso de que o funcionamento normal dos mercados financeiros inevitablemente crea as condicións para unha eventual crise.

Pero, sexan parte da esencia ou froito de impactos esóxenos sobre un sistema esencialmente estable, o certo é que:

- 250 anos de capitalismo documentan a persistencia das crises.

- A súa frecuencia acelérase nos últimos anos (agora é o duplo ca antes de 1914).

- $\quad 0$ seu custo medio é moi elevado (arredor do 16\% do PIB de media) e nalgúns casos poden chegar a ter efectos devastadores.

Esta "normalidade" e "perigosidade" convértennas no principal reto das autoridades monetarias, supervisores e reguladores, os que, a través da regulación post-crise, pretenden reducir a tendencia do sistema a xerar ciclos de expansión e contracción, utilizando para iso a estrutura regulatoria facéndoa anti-cíclica.

Os requirimentos de capital, xunto coas ratios globais de liquidez e apancamento son os instrumentos centrais do enfoque macroprudencial e constitúen o núcleo fundamental da reforma porque,

\section{Os novos requirimentos de capital}

- $\quad$ incrementan substancialmente o capital que os bancos deben manter. No período pre-crise moitos bancos operaban con apancamentos perigosamente elevados polo que pequenas perdas podían poñelos en moi difícil situación, coa conseguinte demanda de apoio con diñeiro público. A ratio media de apancamento na banca comercial era en 2007 de 35 a 1 en EE UU e de 45 a 1 en Europa.

- $\quad$ suavizan o ciclo, xa que varían as esixencias de capital regulatorio ao longo do mesmo, penalizando o crecemento excesivo do crédito na fase ascendente e facilitándoo na descendente. 
Os novos requirimentos de liquidez.

O seu propósito é evitar os riscos asociados á transformación de madurez característica do negocio bancario, riscos que se poden materializar ata en bancos razoablemente ben capitalizados. En efecto, un banco pode ser forzado a vender prematuramente os seus activos ilíquidos para pagar aos seus acredores a curto prazo que retiran os fondos cando chegan os problemas. As perdas asociadas a estas vendas a prezos de saldo poden provocar a quebra dun gran banco, mesmo se estaba ben capitalizado.

\section{$\underline{\text { A ratio suplementaria de apancamento }}$}

Ao contrario dos requirimentos de capital que teñen en conta como ponderacións o diferente risco de cada tipo de activo, estas ratios suplementarias prescinden dos riscos. A súa razón de ser é o recoñecemento de que aqueles requirimentos de capital son inherentemente imperfectos porque nunca capturarán o verdadeiro risco de cada activo. Así, o obxectivo destas ratios é servir como un apoio dos requirimentos de capital, a modo de protección fronte a erros na súa determinación.

\section{OS BANCOS “SISTEMICAMENTE IMPORTANTES"}

Unha segunda tarefa afrontada polos deseñadores da regulación post-crise para reducir os riscos sistémicos foi a de determinar o que facer coas grandes institucións financeiras, complexas e altamente conectadas, que son demasiado grandes para quebrar (too big to fail) porque arrastrarían a todo o sistema, aos que se denomina "bancos sistemicamente importantes" ou, abreviadamente, "bancos sistémicos".

Fronte a "o pequeno é fermoso" de tempos pasados, ao longo das décadas que inmediatamente precederon á crise de 2008, prevaleceu o mito do cabalo grande "ande ou non ande": supostas economías de escala e profesionais de talento excelso crearían unha oligarquía galáctica fronte a outra Banca "aldeá". Pero tales galácticos foron, xustamente, a orixe da gran crise de 2008 e os primeiros en estalar con ela. A xestión, e non o tamaño, revelouse como o factor discriminante na crise.

Reducir o risco sistémico, para que a eficiencia e a disciplina do mercado poidan facer o seu traballo, esixe ter baixo estreito control público a saúde das entidades sistémicas (aquelas cuxa caída, polo seu tamaño e/ou complexidade, poden arrastrar a todo o sistema). Por iso, desenvolvéronse novas regulacións en varias direccións:

- $\quad$ Requirimentos de capital moi superiores ao esixido aos outros bancos e tamén maior atención ao risco de liquidez de modo que se reduzan as probabilidades de necesitar asistencia estatal, se minimice o custo da intervención e se rebaixen os incentivos para crecer. A maior capitalización é unha boa forma de internalizar as externalidades negativas -máis precisamente, os riscos- creados por unha institución para todo sistema.

- $\quad 0$ establecemento de stress testing periódicos e planificación do capital. Antes da gran crise, a inmensa maioría das entidades financeiras eran incapaces de estimar globalmente o risco de sufrir grandes perdas que os puideran levar á quebra. A 
xestión do risco tiña lugar ao nivel das liñas de negocio (empréstito hipotecario, crédito comercial, trading, etc.) e mesmo moitas das maiores institucións fracasaran na combinación destes riscos individuais nunha medida global do risco ao nivel conxunto da entidade. Por iso, o énfase da regulación post-crise no stress testing e a planificación do capital nos maiores bancos constitúe unha das innovacións regulatorias máis útiles, malia os indubidables erros de aplicación rexistrados.

- A "regra de Volcker". Unha boa parte da actividade dos bancos sistemicamente importantes vinculábase á especulación nos mercados capitais, que é moito máis arriscado cá actividade retallista (a única que o goberno ten que salvagardar). Por iso, nas novas regulacións tratouse de penalizar, e mesmo prohibir, aquela actividade por conta propia. 0 problema radica na quasi imposibilidade de distinguir con seguridade entre actividade de creadores de mercado (market-making), onde as compra-vendas de títulos polos bancos se realizan para facilitar liquidez aos seus clientes, e a actividade especulativa, cuxa finalidade é o logro dun lucro especulativo para o propio banco. Esta dificultade de discriminación entre ámbalas dúas operatorias provoca un elevadísimo custo de compliance e levou a algúns autores a suxerir que sería preferible substituíla por unha taxa fixa sobre os tradings books.

- Instrumentos para facilitar o desmantelamento do Banco e a súa reorganización. Existen varios instrumentos deste tipo nas novas regulacións. Entre eles destaca o establecemento da obriga para as entidades de elaborar un Plan de Continxencia, actualizado periodicamente, especificando neste verdadeiro testamento, o "plan para o seu funeral", un conxunto completo de instrucións sobre como se podería desmantelar rapidamente a Institución se xurdise a necesidade. Con iso procúrase:

- $\quad$ Fortalecer a posición negociadora dos reguladores coas entidades sistémicas. Durante a crise de 2008 as autoridades de varios países tiveron que intervir descoñecendo os problemas que poderían emerxer se se deixaba caer a un banco. Os banqueiros sabíanno e aproveitaron este medo ao descoñecido para presionar a favor dun rescate con diñeiro público.

- Forzar á dirección dos Bancos sistémicos a pensar moito máis coidadosamente sobre as complexas estruturas financeiras que crearon e os distintos eidos xeográficos e de negocio nos que se introduciron. E se os banqueiros teñen que explicar cada paso necesario (e as súas consecuencias) para o peche das súas subsidiarias en cada unha das contornas nas que operan, terán seguramente un grande incentivo para simplificar as súas organizacións.

- Poñer ao descuberto outros problemas legais baixo a forma de obrigas contractuais que establecen restricións substanciais ás opcións dos reguladores.

\section{D) OS CONFLITOS DE INTERESE}

Unha das orixes da gran crise, provén da existencia de conflitos de interese de tres tipos:

1) 0 conflito entre os intereses do banco e os dos clientes. Este conflito está na orixe de recomendacións desaxeitadas do banco, tanto con respecto aos investimentos dos seus clientes (polo seu risco -"preferentes"-, pola súa complexidade ou pola baixa rendibilidade), como en relación ao seu endebedamento (hipotecas que se poden 
converter en insoportables para o cliente por estar referenciadas en divisas, polo "chan" aos seus tipos de xuros ou polo carácter variable deles). A asimetría de información e de formación banco/cliente facilita o abuso.

A resposta regulatoria a estes conflitos de interese vén dada pola Unión Europea coa Mifid, cuxa versión III aplícase dende este ano 2018. O seu obxectivo é incrementar a protección do consumidor e a transparencia nos servizos de investimento. En EE UU o máis significativo exemplo de regulación post-crise neste campo está recollido na DoddFrank Wall Street Reform and Consumer Protection Act, firmada por Obama en 2010.

2) Os conflitos de interese no seo do Consello de Administración, cuxa existencia pode favorecer decisións prexudiciais para os intereses, e ata para a mesma supervivencia do Banco. Por exemplo, no caso de conselleiros-clientes, a súa participación na fixación das condicións do seu propio financiamento ou ben, no caso de conselleirosexecutivos, con respecto á escolla do sistema de compensación dos directivos, tema do que xa falamos.

3) Boa parte do nefasto papel xogado nas crises polas Axencias de Rating é consecuencia do conflito de interese creado polo desprazamento nos anos 70 dende o modelo de "pagamento polo investidor" ao de "pagamento polo emisor" que leva ao conflito entre, por unha banda, a procura de lucrativas comisións e, por outra, o rigor do rating a produtos ou entidades. Lamentablemente, ningunha reforma seria se desenvolveu ata hoxe para resolver este problema.

\section{3.-AVALIACIÓN DA SITUACIÓN ACTUAL}

Con toda certeza, a situación actual non é perfecta, pero si é mellor que a existente cando emerxeu a crise e por iso ben se podería aceptar que a nova regulación tivo o efecto de reducir a probabilidade de novas crises no futuro inmediato ou, alomenos, a súa virulencia. Porén, sería pecar de inxenuidade se non se recoñece o risco de que o alcance da nova regulación acabe sendo menor do que se pretendía.

Iso é así porque, conforme se foron afastando os momentos de pánico do outono de 2008 e as economías detiveron a súa caída libre, a vontade de cooperación internacional foise debilitando, tanto pola diversidade de diagnósticos como de intereses nacionais, e a resistencia dos bancos sistemicamente importantes fíxose cada vez maior. En particular, a Administración republicana nos EE UU de Trump xa anunciou un repregamento regulatorio.

Os resultados dun recente estudo sobre as preocupacións do sector financeiro, recordan inquietamente a situación en 2006. En efecto, agora a sobrerregulación ocupa o primeiro lugar na lista, como en 2006, namentres que a xestión do risco está actualmente relegada ao posto $11^{\circ}$, aínda peor có $10^{\circ}$ no que a situaba o estudo referido a 2006.

En tal contexto cómpre recordar o enorme custo das crises financeiras e considerar que, se as modificacións regulatorias son reconducidas a cambios só superficiais, estaríase abrindo paso á perturbadora posibilidade de que unha importante crise nos visite de novo en dez ou quince anos.

Por outra banda, é necesario advertir que, mesmo no caso de que non se relaxen as novas regulacións, e se culminen satisfactoriamente os procesos de cambio normativo hoxe en 
marcha, o sistema financeiro non quedará inmunizado fronte ás crises.

E isto é así porque, en primeiro lugar, os vellos camiños aínda permitirían a posibilidade de que factores desestabilizadores ben coñecidos tiveran novamente a oportunidade de amosar os seus efectos negativos. Así, como meros exemplos:

- Iniciouse a formación de novas burbullas (inmobiliarias e de activos financeiros) nas rexións nas que a recuperación económica é xa significativa (España, grandes zonas urbanas de EE UU, etc.).

- O sector financeiro menos regulado ou, "á sombra" (Compañías de seguros, fondos de investimento e de pensións, hedge funds,...), como reacción á maior severidade regulatoria actual, estase expansionando, e xa sabemos que dende aí contribuíuse xenerosamente á xestación da crise anterior.

- $\quad$ A debilidade da banca dalgúns países europeos (Italia, por exemplo, cun 17\% dos seus empréstitos en situación problemática) ou a debilidade dalgún gran banco (como o renqueante xigante alemán Deustsche Bank), nunha contorna de baixo crecemento e tipos ultra baixos poderían desencadear perturbacións significativas.

Pero, en segundo termo, sen dúbida o maior perigo de crise futura provén do que poderíamos denominar "erro Maginot": Nos anos 30, os franceses adicaron cuantiosos recursos a "blindar" a súa fronteira con Alemaña, tratando de garantir a imposibilidade dunha nova invasión como a que padeceron na primeira guerra mundial. Como é ben sabido, na segunda guerra mundial foron invadidos de novo polos alemáns, pero esta vez, para a súa sorpresa, a través dos Países Baixos. No noso contexto, o "erro Maginot" fai referencia á posibilidade de que non sexan os vellos responsables da crise (as novas regulacións que os pretenden controlar sería a nosa "liña Maginot") os que a provoquen outra vez, senón que sexan outros novos elementos os que detonen unha nova crise global. Pénsese, como simple exemplo ilustrativo, nas posibilidades que ofrece a economía China, co seu universo de subvencións e macro proxectos públicos xeradores dun déficit na contorna do $15 \%$ do PIB e un endebedamento (público e privado) do $250 \%$ do PIB. Ademais, os seus prezos inmobiliarios e de activos financeiros (accións e débedas) disparáronse a niveis ameazantes. Se estas burbullas estoupasen, o yuan afundiríase, creando un grave problema ás economías en desenvolvemento que exportan a China, porque se poderían ver incapaces de servir a súa débeda (denominada en dólares), deixando a moitos prestamistas de países desenvolvidos nunha situación moi delicada.

Pero, máis importante aínda, recordemos que a historia apréndenos que a innovación financeira vai permanentemente por diante da lei e que os bancos sempre atopan enxeñosos camiños para sortear as regulacións. Con iso poden abrir portas á irrupción de novas crises.

Xa ao final da miña intervención, unha advertencia é necesaria. Trátase de distinguir entre "mellor" e "máis" regulación. En efecto, a nivel mundial durante os últimos anos a contorna normativa foi incrementando as súas características de prolixidade e severidade punitiva causando unha transformación certamente significativa na práctica totalidade das áreas de actuación e desenvolvemento das entidades financeiras.

A cantidade e a rapidez con que se suceden os cambios lexislativos comezan a ser abrumadoras, o que xustifica sobradamente o emprego da expresión fatiga regulatoria. 
Sen dúbida, a gran crise de 2008 puxo unha vez máis de relevo o gravísimo custo para un país de dispoñer dunha insuficiente regulación. Pero é preciso recoñecer igualmente que os custos da regulación son tamén moi importantes e que en moitos casos o nivel de regulación é excesivo debido a que o regulador non soporta máis que unha mínima parte dos custos da regulación ("regular" é a política pública menos onerosa).

Ao non recaer o custo da regulación sobre as autoridades, incórrese sistematicamente, a "custo cero", en sobrerregulación, por un lóxico nesgo cara niveis excesivos de seguridade, chegando a situacións nas que os beneficios sociais son inferiores aos custos o a outros casos nos que se prescinde de formulacións que reducirían sensiblemente o custo sen afectar aos beneficios (é dicir, que o contido da regulación é tecnicamente deficiente para acadar os obxectivos perseguidos). Do mesmo xeito que se fala dos "fallos do mercado", tamén cómpre falar dos "fallos do regulador". Isto non é difícil de aceptar se pensamos no modo no que estas decisións se toman, en comités e outros órganos representativos; se consideramos a medida na que as burocracias funcionan ineficientemente e, finalmente, se recordamos o modo no que os gobernos e supervisores consideran os intereses dos diferentes grupos de interese á hora de establecer os contidos da regulación.

A prolixa regulación resultante peca de déficit democrático (porque a inmensa maioría de cidadáns e mesmo dos seus representantes no congreso non teñen nin idea do que significan nin dos seus probables efectos) e impoñen un custo de xestión e de compliance considerables (pénsese na lei Dodd-Frank coas súas 2600 páxinas). Todo iso fai que o custo soportado polas entidades financeiras sexa enorme e, o que é peor, en parte innecesario. Como exemplo ilustrativo cabe sinalar que algún dos bancos sistemicamente importantes ten a máis de 10.000 empregados adicados ao cumprimento normativo.

É evidente que este escenario non pode resultar satisfactorio para ninguén. Elementais razóns de eficiencia económica e política impoñen a necesidade de reconfigurar o sistema (e a filosofía) de produción de normas. As autoridades públicas deben tomar conciencia da fatiga regulatoria que acusa o sector produtivo e adoptar as iniciativas oportunas para reconducir a situación.

En primeiro lugar sería moi conveniente que se propuxesen ambiciosas metas de redución dos custos de cumprimento da regulación que hoxe pesa sobre a banca.

En segundo lugar, deberían poñer ao día os mecanismos de produción normativa, tanto incorporando realmente a análise custo-beneficio, ou valoración de impactos, como reforzando a publicidade do proceso, dando maior transparencia ao proceso en si mesmo, publicando as memorias explicativas dos proxectos, así como as distintas versións dos textos (dende os primeiros momentos da súa elaboración). Só así serviríase eficazmente ao obxectivo último de crear un sistema financeiro que acheguen soporte ao crecemento económico mediante a mellor combinación de estabilidade, imposta polo estado, e o poder creador da iniciativa privada, canalizada polos mercados.

Revista Galega de Economía: http://www.usc.es/econo/RGE/benvidag.htm 